\title{
EFEITOS DO MANEJO DE ADUBAÇÃo POTÁSSICA, COM E SEM ADIÇÃO DE FONTE DE CÁLCIO SOBRE O RENDIMENTO DE GRÃOS E SEUS COMPONENTES NA CULTURA DA SOJA
}

\section{ARTIGO ORIGINAL}

SILVA, Jean Augusto Bueno da ${ }^{1}$, JEZIORSKI, Cleiton Luís ${ }^{2}$, KLARMANN, Paulo André $^{3}$

SILVA, Jean Augusto Bueno da. JEZIORSKI, Cleiton Luís. KLARMANN, Paulo André. Efeitos do manejo de adubação potássica, com e sem adição de fonte de cálcio sobre o rendimento de grãos e seus componentes na cultura da soja. Revista Científica Multidisciplinar Núcleo do Conhecimento. Ano. 07, Ed. 02, Vol. 02, pp. 35-53. Fevereiro de 2022. ISSN: 2448-0959, Link de acesso: https://www.nucleodoconhecimento.com.br/agronomia/adubacao-potassica

\section{RESUMO}

A correta adubação é um dos fatores mais importantes e imprescindível para um bom desenvolvimento, em termos de produtividade, na cultura da soja. Neste contexto, o problema de pesquisa levantado foi: os componentes de rendimento e o rendimento de grãos da soja são afetados significativamente pelos manejos de adubação potássica acrescida de adição anual de cálcio nas condições edafoclimáticas de Três de Maio - RS, nas duas safras em estudo? O presente estudo objetivou a avaliação do efeito dos diferentes manejos de adubação potássica, com e sem a adição de uma fonte de cálcio, sobre o rendimento de grãos e seus componentes na cultura da soja nas condições de clima e solo do município de Três de Maio- RS, nos anos-safra 2019/20 e 2020/21. Para o levantamento dos dados numéricos utilizou-se do método

\footnotetext{
${ }^{1}$ Bacharel em Agronomia. ORCID: 0000-0002-6849-2174.

${ }^{2}$ Bacharel em Agronomia. ORCID: 0000-0002-2493-0208.

${ }^{3}$ Orientador.
}

Disponível em: https://www.nucleodoconhecimento.com.br/agronomia/adubacaopotassica 
de abordagem quantitativa, os métodos de procedimentos utilizados foram os métodos de procedimento estatístico e experimental. Empregou-se a observação direta intensiva por observação, para a coleta e para a análise de dados foi utilizada a estatística descritiva e inferencial. Quanto à densidade de plantas, não houve diferença significativa entre os tratamentos. Em relação ao componente densidade de legumes a média encontrada foi de 992 legumes $/ \mathrm{m}^{2}$, não diferindo estatisticamente entre os tratamentos. O número de grãos por legume também não apresentou diferença significativa entre os tratamentos. Quanto ao componente massa de mil grãos também não foram encontradas diferenças significativas entre os tratamentos nos dois anos de cultivo. Em relação ao rendimento de grãos, na safra 2019/20 a média rendimento foi de $2465 \mathrm{~kg} \mathrm{ha}^{-1}$ enquanto na que safra 2020/21 o rendimento médio foi de $4214 \mathrm{~kg} \mathrm{ha}^{-1}$, sendo que em ambas as safras não houve diferenças significativas de rendimento entre os tratamentos. Com base nos resultados obtidos no presente estudo, pode-se concluir que os componentes de rendimento e rendimento de grãos não sofreram influência quanto ao manejo de aplicação de potássio e a adição de uma fonte de cálcio na cultura da soja, em latossolos com altos níveis de fertilidade.

Palavras-chave: Glycine max, Produção de grãos, Manejo de adubação.

\section{INTRODUÇÃO}

A soja (Glycine max) tem grande destaque na economia mundial na safra 2009/2010 a produção foi de 259,7 milhões de toneladas onde foram cultivados cerca de 102 milhões de hectares (USDA, 2011). No Brasil, a grande produtividade configura o país como o segundo maior produtor mundial desta oleaginosa, sendo assim uma das principais commodities no mercado brasileiro do agronegócio (USDA, 2011).

Esta melhoria contínua na produtividade da soja ocorre em virtude de novas tecnologias desenvolvidas para incrementar o rendimento por área, pois o desafio é produzir mais nas mesmas áreas, por isso é importante saber qual o melhor manejo de adubação a ser adotado para alcançar maiores rendimentos.

RC: 106378

Disponível em: https://www.nucleodoconhecimento.com.br/agronomia/adubacaopotassica 
A grande dúvida surge no momento de pré-plantio onde está sendo definido a forma de aplicação dos nutrientes, pois existem dois meios de se fazer, a lanço ou na linha de plantio. Conforme Tomé (2019) o modo de aplicação pode alterar a velocidade e a capacidade dos fertilizantes no solo, havendo diferença quando aplicado a lanço ou na linha de semeadura.

O conhecimento destes manejos é fundamental para o incremento da produção, pois a produtividade depende da forma de adubação e sua aplicação. Tomé (2019) estabelece que adubação na linha é quando se realiza junto com o plantio e aplicação a lanço é realizada na superfície do solo onde pode ser antes ou após o plantio.

O potássio é um dos elementos fundamentais para o desenvolvimento da cultura da soja, pois ele ajuda na formação da parede celular e no transporte de nutrientes para o enchimento dos grãos, gerando assim maior produtividade e estabilidade para a cultura (MALAVOLTA, 2006).

Os nutrientes Cálcio e Magnésio possuem comportamentos similares sendo absorvidos como componentes da matéria orgânica, e pouco absorvidos quando o pH for muito alto segundo Raij (2011).

De acordo com Melém Júnior et al. (2015) a cultura da soja apresentou acréscimo na produtividade com o incremento da adubação potássica, ou seja, sem a adição desse nutriente a produtividade foi de $1943 \mathrm{~kg} \mathrm{ha}^{-1}$ e com $90 \mathrm{~kg} \mathrm{ha}^{-1}$ de $\mathrm{K}_{2} \mathrm{O}$ a produtividade foi de $2.572 \mathrm{~kg} \mathrm{ha}^{-1}$, assim como a número de legumes por planta. Ainda conforme Marcos Filho (2005) uma nutrição adequada influencia diretamente no tamanho e peso dos grãos das culturas.

Portanto, sabendo-se da importância dos nutrientes para o desenvolvimento da cultura da soja, Reetz (2017) afirma a importância dos fertilizantes para a recuperação da fertilidade do solo e também para o aumento de produtividade das culturas. Com isso é importante que estudos sejam realizados para a comparação de efetividade dos

RC: 106378

Disponível em: https://www.nucleodoconhecimento.com.br/agronomia/adubacaopotassica 
diferentes manejos de aplicação da adubação potássica com a utilização de cálcio para o incremento de produção.

O correto manejo da fertilidade do solo é uma condição essencial para o sucesso de toda e qualquer cultura, como também para a cultura da soja. Identificar a capacidade que o solo possui para fornecer os nutrientes às plantas e planejar as estratégias apropriadas de manejo da adubação são decisões importantes para que se alcance altas produtividades. Para isso, se torna indispensável a realização de análise de solo.

Neste contexto, o problema de pesquisa levantado foi: os componentes de rendimento e o rendimento de grãos da soja são afetados significativamente pelos manejos de adubação potássica acrescida de adição anual de cálcio nas condições edafoclimáticas de Três de Maio - RS, nas duas safras em estudo? O presente estudo objetivou a avaliação do efeito dos diferentes manejos de adubação potássica, com e sem a adição de uma fonte de cálcio, sobre o rendimento de grãos e seus componentes na cultura da soja nas condições de clima e solo do município de Três de Maio- RS, nos anos-safra 2019/20 e 2020/21.

\section{ASPECTOS METODOLÓGICOS}

Através do desenvolvimento deste trabalho de pesquisa buscou-se avaliar os efeitos do manejo de adubação potássica, com e sem a adição de uma fonte de cálcio, sobre o rendimento de grãos e seus componentes na cultura da soja.

Para tanto formulou-se o seguinte problema: Os componentes de rendimento e o rendimento de grãos da soja são afetados significativamente pelos manejos de adubação potássica acrescida de adição anual de cálcio nas condições edafoclimáticas do município de Três de Maio- RS, safras 2019/20 e 2020/21?

As hipóteses formuladas para auxiliarem na resolução do problema foram:

A adubação potássica, quando realizada em superfície, a lanço, irá promover incrementos significativamente maiores no rendimento de grãos, em relação à RC: 106378

Disponível em: https://www.nucleodoconhecimento.com.br/agronomia/adubacaopotassica 
aplicação no sulco de semeadura, em ambos os anos de cultivo; Os componentes de rendimento da soja no segundo cultivo são afetados significativamente pelos tratamentos nutricionais estudados; Quando adicionada uma fonte de cálcio nos tratamentos realizados, ocorre aumento significativo na massa de mil grãos da soja em ambos os cultivos, independentemente do manejo da adubação potássica; $O$ uso de uma fonte de cálcio no solo promove menor extração de potássio pelas plantas de soja aos 30, 60, 90 dias e pelos grãos, na condição do segundo cultivo, independentemente de sua forma de aplicação; $O$ uso de uma fonte de cálcio por dois anos consecutivos, afeta de modo significativo o rendimento de grãos da soja no segundo cultivo, devido ao efeito residual desse elemento no solo.

Utilizou-se dos métodos de abordagem quantitativa para a coleta e análise dos dados referentes aos componentes de rendimento (densidade de plantas, densidade de legumes, número de grãos por legume e massa de mil grãos), rendimento de grãos e concentração de nutrientes na fitomassa da cultura.

Os métodos de procedimento utilizados foram o estatístico e o experimental. $\mathrm{O}$ procedimento estatístico foi empregado para a análise numérica dos dados (densidade de plantas, densidade de legumes, número de grãos por legume, massa de mil grãos, concentrações de nutrientes na fitomassa da cultura e rendimento de grãos). já o procedimento experimental foi utilizado no delineamento e condução do ensaio no campo, tendo um tratamento como testemunha

A coleta de dados foi através da observação direta intensiva por observação, empregada para a coleta dos dados numéricos referentes ao rendimento de grãos, bem como os componentes de rendimento. E para a análise dos dados foram utilizadas a estatística descritiva e inferencial, através da análise de variância (ANOVA) e os valores foram comparados através teste de Tukey a $5 \%$ de probabilidade de erro.

RC: 106378

Disponível em: https://www.nucleodoconhecimento.com.br/agronomia/adubacaopotassica 
A população em estudo trata-se do conjunto de plantas de soja da cultivar M 6410 IPRO, que apresenta hábito de crescimento indeterminado de grupo de maturação 6.4, compondo as diversas parcelas que compuseram o experimento de campo.

Para avaliação do rendimento de grãos e massa de mil grãos foram utilizados os grãos que foram colhidos na área útil das parcelas, sendo esta composta por quatro metros das 3 linhas centrais. Para a avaliação dos componentes de rendimento e determinação dos nutrientes presentes na fitomassa foram utilizadas as plantas da área destrutiva, composta por 1,5 metros de cada uma das extremidades das parcelas.

O estudo em tela teve experimento implantado à campo na localidade de Vila Manchinha, município de Três de Maio, nas coordenadas $27^{\circ} 42^{\prime} 13^{\prime \prime}$ S e 54 $4^{\circ} 13^{\prime} 53^{\prime \prime}$ a uma altitude 308 metros em relação ao nível do mar e o solo é classificado como Latossolo Vermelho Distroférrico Típico (EMBRAPA, 2013), o experimento foi implantado sob sistema de semeadura direta sendo a cultura do trigo o cultivo antecedente.

O delineamento experimental ocorreu por blocos inteiramente casualizados distribuídos em 6 tratamentos e 4 repetições, totalizando 24 parcelas com dimensões de 2,5 metros de largura por 7 metros de comprimento.

Em relação a quantidade de fertilizantes utilizada, na safra 2019/20, em condição de primeiro cultivo, os tratamentos T1 e T2 receberam $234 \mathrm{~kg} \mathrm{ha}^{-1}$ do adubo formulado NPK (02.23.23), aplicado na linha de semeadura, os tratamentos T3 e T4 receberam $118 \mathrm{~kg} \mathrm{ha}^{-1}$ de SF + $25 \mathrm{~kg}$ ha-1 de $\mathrm{KCl}$, aplicado na linha de semeadura, e os tratamentos T5 e T6 receberam $118 \mathrm{~kg} \mathrm{ha}^{-1}$ de SFT na linha de semeadura $+25 \mathrm{~kg}$ ha $^{-1}$ de $\mathrm{KCl}$, aplicado em superfície.

Na safra 2020/21, em condição de segundo cultivo, os tratamentos T1 e T2 receberam $390 \mathrm{~kg} \mathrm{ha}^{-1}$ do adubo formulado NPK (02.23.23), aplicado na linha de semeadura, os tratamentos T3 e T4 receberam $120 \mathrm{~kg} \mathrm{ha}^{-1}$ de SFT + $150 \mathrm{~kg} \mathrm{ha}^{-1}$ de KCl, aplicado na

RC: 106378

Disponível em: https://www.nucleodoconhecimento.com.br/agronomia/adubacaopotassica 
linha de semeadura, e os tratamentos T5 e T6 receberam $120 \mathrm{~kg} \mathrm{ha}^{-1}$ de SFT na linha de semeadura $+150 \mathrm{~kg} \mathrm{ha}^{-1}$ de $\mathrm{KCl}$ aplicado em superfície.

Já o fertilizante à base de cálcio, Fort Cal $(38 \% \mathrm{Ca}+0,5 \% \mathrm{Mg})$ foi aplicado somente nos tratamentos T2, T4 e T6, em superfície, na dose fixa de $200 \mathrm{~kg} \mathrm{ha}^{-1}$.

As parcelas foram compostas de 5 linhas, espaçadas em $50 \mathrm{~cm}$ entre linhas e sete metros de comprimento, perfazendo uma área de $17,5 \mathrm{~m}^{2}$, a qual foi dividida em área útil e área destrutiva. $\mathrm{Na}$ área útil foi realizada a colheita de quatro metros das 3 linhas centrais para aferir o rendimento de grãos. Desses grãos colhidos foram efetuadas amostras para determinação da massa de mil grãos e da concentração de $\mathrm{Ca}, \mathrm{Mg} \mathrm{e}$ $\mathrm{K}$ nos grãos.

\section{REFERENCIAL TEÓRICO}

As primeiras plantas de soja, a mais de 5 mil anos, possuíam característica de uma planta rasteira, e após cruzamentos naturais entre duas espécies de soja selvagem, foram domesticadas e melhoradas por cientistas da antiga China (DALL'AGNOL et al., 2007), dando origem a uma soja muito similar à que é atualmente cultivada.

Segundo dados da CONAB (2020), a produção do grão no Brasil para a safra 2019/20 atingiu os 120,3 milhões de toneladas, um recorde na série histórica, representando um acréscimo de 4,6\% em relação ao exercício passado. No Rio Grande do Sul, a produção foi de aproximadamente 25.970 mil toneladas, colocando o estado entre os 5 maiores produtores de soja do país.

A fertilidade do solo é a capacidade do solo em fornecer elementos essenciais às plantas e, segundo Lopes e Guilherme (2007, p. 1) é um dos componentes mais importantes para o desenvolvimento da agricultura, principalmente no que diz respeito ao aumento da produtividade agrícola. Contudo, para se atingir elevada produtividade, as plantas necessitam de mais nutrientes do que aqueles supridos pelo solo,

Disponível em: https://www.nucleodoconhecimento.com.br/agronomia/adubacaopotassica 
necessitando assim da utilização de insumos contendo nutrientes para manter os solos férteis.

O manejo da fertilização interfere na eficiência dos fertilizantes e a adoção de diferentes métodos de aplicação deve contemplar o aspecto operacional, agronômico e econômico (FIORIN, VOGEL; BORTOLOTTO, 2016). Logo, o modo de aplicação pode alterar a velocidade e a capacidade dos fertilizantes em reagir no solo, sendo por tanto, diferente quando o adubo é aplicado a lanço ou junto com a semeadura (TOMÉ, 2019).

Tomé (2019) define a adubação na linha como sendo a aplicação de fertilizantes e sementes ao mesmo tempo na linha de semeadura, enquanto que a adubação a lanço como sendo aquela aplicação de fertilizantes de forma superficial no solo, geralmente ocorrendo antes da semeadura.

Em muitos casos, de acordo com Fiorin, Vogel e Bortolotto (2016, p. 95) “...as aplicações a lanço podem não fornecer as quantidades de nutrientes necessárias ao desenvolvimento inicial das plantas ao passo que aplicações na linha, em doses elevadas, podem resultar em danos no sistema radicular".

O potássio é o segundo nutriente mais absorvido pelas plantas cultivadas e a manutenção de teores adequados deste nutriente em solos agrícolas requer especial atenção (BENITES et al., 2010; PRADO, 2008).

Tratando-se de cálcio e magnésio, ambos ocorrem, no solo, nas formas catiônicas $\left(\mathrm{Ca}^{2+}\right.$ e $\left.\mathrm{Mg}^{2+}\right)$. O cálcio encontra-se adsorvido nos colóides do solo (Ca - trocável) ou como componente da matéria orgânica, podendo precipitar como carbonatos, fosfatos ou sulfatos pouco solúveis quando o pH for elevado (RAIJ, 2011; PRADO, 2008; TROEH; THOMPSON, 2007). Devido a concentração baixa de cálcio em solos ácidos, recomenda-se a utilização de corretivos como calcários (carbonatos de cálcio) que além de neutralizar a acidez atuam como fonte importante de cálcio.

RC: 106378

Disponível em: https://www.nucleodoconhecimento.com.br/agronomia/adubacaopotassica 
A assimilação do potássio pelas plantas se dá na forma iônica $\left(\mathrm{K}^{+}\right)$, ocorrendo por vários sistemas (transportadores e em canais) (PRADO, 2008) e depende principalmente da difusão do elemento através da solução do solo, podendo acontecer também por fluxo em massa (RAIJ, 2011). Dentre os fatores que podem afetar a absorção de potássio pelas plantas estão a umidade, a concentração do nutriente no solo e a idade da planta, onde raízes mais jovens apresentam maior absorção se comparado com raízes velhas (PRADO, 2008). Após a absorção, o potássio é transportado rapidamente via xilema para a parte aérea (MALAVOLTA, 2006).

Tratando-se de cálcio, as formas pelas quais ele pode ser absorvido pelas plantas é como íon $\mathrm{Ca}^{2+}$ e o cálcio quelatizado (MALAVOLTA, 2006). Sua absorção não ocorre somente por fluxo em massa, mas também através da interceptação radicular (PRADO, 2008) e seu transporte após atingir o xilema ocorre de forma passiva e acropétalo, ou seja, é unidirecional (MALAVOLTA, 2006).

No caso das interações entre $\mathrm{K}, \mathrm{Ca}$ e $\mathrm{Mg}$, um aumento na dose de $\mathrm{K}$ causa decréscimo nos teores de $\mathrm{Ca}$ e $\mathrm{Mg}$, assim como a interação entre $\mathrm{Ca}$ e $\mathrm{Mg}$ na solução do solo é antagônica, ou seja, o excesso de um prejudica a absorção do outro (PRADO, 2008; MOORE, OVERSTREET; JACOBSON, 1961).

\section{APRESENTAÇÃO E DISCUSSÃO DOS RESULTADOS}

Com relação a concentração de nutrientes na fitomassa da cultura, foi realizada análise laboratorial para a determinação da concentração de K, Ca e Mg aos 30, 60 e 90 dias após a emergência (D.A.E) buscando identificar a absorção destes nutrientes pelas plantas em diferentes estádios de desenvolvimento da cultura, conforme apresentado na figura 1.

RC: 106378

Disponível em: https://www.nucleodoconhecimento.com.br/agronomia/adubacaopotassica 
Figura 1 - Concentração de K, Ca e Mg na fitomassa da cultura aos 30, 60 e 90 D.A.E

\begin{tabular}{|c|c|c|c|c|c|c|c|c|c|}
\hline \multirow{2}{*}{ Tratamento } & \multicolumn{3}{|c|}{30 D.A.E } & \multicolumn{3}{c|}{ 60 D.A.E } & \multicolumn{3}{c|}{90 D.A.E } \\
\cline { 2 - 10 } & K\% & Ca\% & Mg\% & K\% & Ca\% & Mg\% & K\% & Ca\% & Mg\% \\
\hline T1 & $2,20 \mathrm{a}$ & $1,78 \mathrm{a}$ & $0,80 \mathrm{a}$ & $2,73 \mathrm{a}$ & $1,47 \mathrm{a}$ & $0,40 \mathrm{a}$ & $2,08 \mathrm{a}$ & $0,60 \mathrm{a}$ & $0,45 \mathrm{a}$ \\
\hline T2 & $2,32 \mathrm{a}$ & $1,81 \mathrm{a}$ & $0,69 \mathrm{a}$ & $2,51 \mathrm{a}$ & $1,35 \mathrm{a}$ & $0,44 \mathrm{a}$ & $2,22 \mathrm{a}$ & $0,54 \mathrm{a}$ & $0,39 \mathrm{a}$ \\
\hline T3 & $2,52 \mathrm{a}$ & $1,77 \mathrm{a}$ & $0,66 \mathrm{a}$ & $2,87 \mathrm{a}$ & $1,47 \mathrm{a}$ & $0,44 \mathrm{a}$ & $2,13 \mathrm{a}$ & $0,63 \mathrm{a}$ & $0,43 \mathrm{a}$ \\
\hline T4 & $2,37 \mathrm{a}$ & $2,04 \mathrm{a}$ & $0,86 \mathrm{a}$ & $2,93 \mathrm{a}$ & $1,33 \mathrm{a}$ & $0,41 \mathrm{a}$ & $2,24 \mathrm{a}$ & $0,73 \mathrm{a}$ & $0,42 \mathrm{a}$ \\
\hline T5 & $2,32 \mathrm{a}$ & $1,99 \mathrm{a}$ & $0,85 \mathrm{a}$ & $2,66 \mathrm{a}$ & $1,44 \mathrm{a}$ & $0,44 \mathrm{a}$ & $2,13 \mathrm{a}$ & $0,70 \mathrm{a}$ & $0,44 \mathrm{a}$ \\
\hline T6 & $2,50 \mathrm{a}$ & $2,06 \mathrm{a}$ & $0,87 \mathrm{a}$ & $3,09 \mathrm{a}$ & $1,57 \mathrm{a}$ & $0,44 \mathrm{a}$ & $2,01 \mathrm{a}$ & $0,69 \mathrm{a}$ & $0,44 \mathrm{a}$ \\
\hline Média & 2,38 & 1,91 & 0,79 & 2,80 & 1,44 & 0,43 & 2,14 & 0,65 & 0,43 \\
\hline C.V (\%) & 11,62 & 9,98 & 12,56 & 11,8 & 15 & 18,99 & 6,78 & 18,27 & 10,45 \\
\hline
\end{tabular}

T1 - Testemunha (adubo N-P-K 02.23.23), T2 - N-P-K 02.23.23 + Cálcio, T3 - SFT + $\mathrm{KCl}$ (linha), T4 $-\mathrm{SFT}+\mathrm{KCl}$ (linha) + Cálcio, T5 $-\mathrm{SFT}+\mathrm{KCl}$ (lanço), T6 $-\mathrm{SFT}+\mathrm{KCl}$ (lanço) + Cálcio. Médias seguidas de mesma letra, na coluna, não diferem entre si no $\begin{array}{lllllll}\text { teste de tukey a } & 5 & \% & \text { de } & \text { significância. }\end{array}$ Fonte: Klarmann; Silva; Jeziorski (2021)

Aos 30 D.A.E, houve maior absorção de $\mathrm{Ca}, \mathrm{Mg}$ e $\mathrm{K}$ pelas plantas nos tratamento em que foi realizada aplicação de fertilizante a base de cálcio, porém não apresentou diferença estatística em relação aos demais tratamentos, esse aumento na absorção de nutrientes pode estar relacionado aos altos índices pluviométricos nos meses de dezembro e janeiro, com volumes chuvas mensal acima de 220 milímetros, facilitando assim a dissolução dos fertilizantes e fazendo com que os nutrientes estivessem disponíveis na solução do solo.

Já aos 60 D.A.E, foi observado uma pequena elevação na concentração de $\mathrm{Ca}, \mathrm{Mg}$ e $\mathrm{K}$, no tratamento 6 (SFT + KCl (lanço) + Cálcio), porém essa diferença também não foi significativa em comparação aos demais tratamentos.

Os valores encontrados aos 90 D.A.E apresentam maiores concentrações de $\mathrm{Ca}$ e K no tratamento 4 (SFT+KCl (linha) + Cálcio), porém as maiores concentrações de $\mathrm{Mg}$ foram encontradas no tratamento 1 (N-P-K 02.23.23), porém como nas épocas

Disponível em: https://www.nucleodoconhecimento.com.br/agronomia/adubacaopotassica 
anteriores não apresentaram diferenças significativas em relação aos demais tratamentos.

A Figura 2 apresenta os teores de potássio, cálcio e magnésio presentes nos grãos da cultura da soja nas safras 2019/20 e 2020/21.

Figura 2 - Teores K, Ca e Mg nos grãos da soja nas safras 2019/20 e 2020/21

\begin{tabular}{|c|c|c|c|c|c|c|}
\multirow{2}{*}{ Tratamento } & \multicolumn{3}{|c|}{$\mathbf{2 0 1 9 / 2 0 2 0}$} & \multicolumn{3}{|c|}{$\mathbf{2 0 2 0 / 2 0 2 1}$} \\
\cline { 2 - 7 } & $\mathbf{K} \%$ & $\mathbf{C a} \%$ & $\mathbf{M g} \%$ & $\mathbf{K} \%$ & $\mathbf{C a} \%$ & $\mathbf{M g} \%$ \\
\hline T1 & $1,89 \mathrm{a}$ & $0,27 \mathrm{a}$ & $0,24 \mathrm{a}$ & $1,92 \mathrm{a}$ & $0,27 \mathrm{a}$ & $0,25 \mathrm{a}$ \\
\hline T2 & $1,98 \mathrm{a}$ & $0,27 \mathrm{a}$ & $0,25 \mathrm{a}$ & $1,95 \mathrm{a}$ & $0,27 \mathrm{a}$ & $0,25 \mathrm{a}$ \\
\hline T3 & $1,88 \mathrm{a}$ & $0,27 \mathrm{a}$ & $0,25 \mathrm{a}$ & $2,00 \mathrm{a}$ & $0,27 \mathrm{a}$ & $0,25 \mathrm{a}$ \\
\hline T4 & $2,16 \mathrm{a}$ & $0,27 \mathrm{a}$ & $0,27 \mathrm{a}$ & $1,92 \mathrm{a}$ & $0,26 \mathrm{a}$ & $0,25 \mathrm{a}$ \\
\hline T5 & $1,90 \mathrm{a}$ & $0,27 \mathrm{a}$ & $0,24 \mathrm{a}$ & $1,93 \mathrm{a}$ & $0,27 \mathrm{a}$ & $0,25 \mathrm{a}$ \\
\hline T6 & $1,94 \mathrm{a}$ & $0,27 \mathrm{a}$ & $0,26 \mathrm{a}$ & $1,91 \mathrm{a}$ & $0,28 \mathrm{a}$ & $0,24 \mathrm{a}$ \\
\hline Média & 1,96 & 0,27 & 0,25 & 1,94 & 0,27 & 0,25 \\
\hline C.V (\%) & 6,37 & 1,65 & 6,46 & 2,1 & 2,5 & 2,9 \\
\hline
\end{tabular}

${ }^{*} T 1$ - Testemunha (adubo N-P-K 02.23.23), T2 - N-P-K 02.23.23 + Cálcio, T3 - SFT + $\mathrm{KCl}$ (linha), T4 - SFT + KCl (linha) + Cálcio, T5 - SFT + KCl (lanço), T6 - SFT + KCl (lanço) + Cálcio. Médias seguidas de mesma letra, na coluna, não diferem entre si no teste de tukey a 5 \% de significância. Fonte: Klarmann; Silva; Jeziorski (2021)

Em relação a análise da concentração de nutrientes presentes nos grãos da cultura da soja, podemos observar que na safra 2019/20 houve um pequeno acréscimo na concentração de Potássio e Magnésio nos tratamentos onde foi realizada a aplicação de cálcio, porém estes valores não se diferiram estatisticamente em relação aos tratamentos em que não foi realizado a aplicação deste fertilizante.

Já em relação ao Cálcio, o mesmo não apresentou nenhuma diferença em relação à sua concentração nos grãos da cultura da soja na safra 2019/20.

RC: 106378

Disponível em: https://www.nucleodoconhecimento.com.br/agronomia/adubacaopotassica 
$\mathrm{Na}$ safra 2020/21 foram encontradas maiores concentrações de potássio no tratamento 4, onde foi realizada adubação com SFT + $\mathrm{KCl}$ (linha), porém essa diferença não foi significativa em relação a concentração de potássio nos grãos dos demais tratamentos.

Em relação ao cálcio, observa-se que na safra 2020/21 a maior concentração foi encontrada no tratamento 6 , onde foi realizada adubação com SFT + KCl (lanço) + Cálcio, porém também não apresentou diferença significativa em relação aos demais tratamentos.

O mesmo ocorreu com em relação à concentração de Magnésio nos grãos, onde não foram encontradas diferenças em relação às diferentes formas de aplicação de potássio na adubação da cultura e a adição, ou não de fertilizante à base de cálcio.

A figura 3 apresenta os dados referente a densidade de legumes (DL) de cada um dos tratamentos em estudo, na safra 2020/21.

Figura 3 - Densidade de legumes na safra 2020/21.

\begin{tabular}{|l|c|}
\hline \multicolumn{1}{|c|}{ Tratamento } & Densidade legumes $\left(\mathrm{m}^{2}\right)$ \\
\hline T1 - Testemunha (N-P-K 02.23.23) & $1020 \mathrm{a}$ \\
\hline T2 - N-P-K 02.23.23 + Cálcio & $899 \mathrm{a}$ \\
\hline T3 - SFT + KCl (linha) & $874 \mathrm{a}$ \\
\hline T4 - SFT + KCl (linha) + Cálcio & $1001 \mathrm{a}$ \\
\hline T5 - SFT + KCl (lanço) & $1008 \mathrm{a}$ \\
\hline T6- SFT + KCl (lanço) + Cálcio & $1156 \mathrm{a}$ \\
\hline Média & 992 \\
\hline C.V (\%) & 14,71 \\
\hline
\end{tabular}

Médias seguidas de mesma letra, na coluna, não diferem entre si no teste de tukey a 5\% de significância. Fonte: Klarmann; Silva; Jeziorski (2021)

RC: 106378

Disponível em: https://www.nucleodoconhecimento.com.br/agronomia/adubacaopotassica 
Em relação a densidade de legumes verificou-se que não houve diferença significativa entre os tratamentos, sendo que a média encontrada foi de 992 legumes $\mathrm{m}^{2}$, onde que a maior densidade (1155 legumes $\mathrm{m}^{2}$ ) foi observada onde foi utilizado SFT+KCl (lanço) + Cálcio (T6), já a menor densidade (874 legumes $\mathrm{m}^{2}$ ) foi encontrada no T3 $(\mathrm{SFT}+\mathrm{KCl}($ linha)).

Quanto a forma de aplicação de potássio, Mantovani et al. (2017), afirmam em estudo realizado que o método de aplicação de potássio não teve influência significativa no número de legumes por planta, tanto na aplicação do potássio toda em linha de semeadura e todo potássio aplicado em superfície, como também não houve diferença estatística em relação à testemunha, sem aplicação de potássio, em solo com altos teores deste nutriente.

Quanto ao número de grãos por legume na safra 2020/21, observa-se na figura 4 os resultados obtidos.

Figura 4 - Número de grãos por legume na safra 2020/21.

\begin{tabular}{|l|c|}
\hline \multicolumn{1}{|c|}{ Tratamento } & Número de gräos/legume \\
\hline T1 - Testemunha (N-P-K 02.23.23) & $2,5 \mathrm{a}$ \\
\hline T2 - N-P-K 02.23.23 + Cálcio & $2,5 \mathrm{a}$ \\
\hline T3 - SFT + KCl (linha) & $2,5 \mathrm{a}$ \\
\hline T4 - SFT + KCl (linha) + Cálcio & $2,5 \mathrm{a}$ \\
\hline T5 - SFT + KCl (lanço) & $2,5 \mathrm{a}$ \\
\hline T6- SFT + KCl (lanço) + Cálcio & $2,4 \mathrm{a}$ \\
\hline \multicolumn{1}{c|}{ Média } & 2,49 \\
\hline \multicolumn{1}{c|}{ C.V (\%) } & 3,77 \\
\hline
\end{tabular}

Médias seguidas de mesma letra, na coluna, não diferem entre si no teste de tukey a 5\% de significância. Fonte: Klarmann; Silva; Jeziorski (2021) 
Conforme apresentado na figura 4, pode-se observar que se obteve uma média de 2,49 grãos por legume, não apresentando diferença significativa entre os tratamentos em estudo, este resultado pode ser explicado em decorrência dos níveis de nutrientes encontrados no solo estarem altos para o fósforo e muito alto para o potássio.

Em estudo realizado por Peter et al (2016), afirmam não ter encontrado diferenças significativas no número de grãos por legume quanto às diferentes formas de aplicações de fertilizantes, corroborando com o estudo em questão.

Conforme os dados apresentados na figura 06, em relação a massa de mil grãos (MMG), a média obtida nos tratamentos em estudo foi de $128,71 \mathrm{gr}$ na safra $2018 / 20$ e 130,2 na safra $2020 / 21$.

Figura 5 - Massa de mil grãos nas safras 2019/20 e 2020/21.

\begin{tabular}{|l|c|c|}
\hline \multicolumn{1}{|c|}{ Tratamento } & $\mathbf{2 0 1 9 / 2 0 2 0} \mathbf{( g )}$ & $\mathbf{2 0 2 0 / 2 0 2 1} \mathbf{( g )}$ \\
\hline T1 - Testemunha(N-P-K 02.23.23) & $128,75 \mathrm{a}$ & $128,50 \mathrm{a}$ \\
\hline T2 - N-P-K 02.23.23 + Cálcio & $125,75 \mathrm{a}$ & $129,25 \mathrm{a}$ \\
\hline T3 - SFT + KCl (linha) & $125,00 \mathrm{a}$ & $129,75 \mathrm{a}$ \\
\hline T4 - SFT + KCl (linha) + Cálcio & $128,50 \mathrm{a}$ & $132,75 \mathrm{a}$ \\
\hline T5 - SFT + KCl (lanço) & $125,50 \mathrm{a}$ & $130,50 \mathrm{a}$ \\
\hline T6- SFT + KCl (lanço) + Cálcio & $126,75 \mathrm{a}$ & $131,00 \mathrm{a}$ \\
\hline Média & 126,71 & 130,2 \\
\hline C.V (\%) & 2,65 & 2,71 \\
\hline
\end{tabular}

Médias seguidas de mesma letra na coluna não diferem entre si no teste de tukey a 5\% de significância. Fonte: Klarmann; Silva; Jeziorski (2021)

Ao mencionarmos o componente de rendimento (MMG), podemos observar na figura 06, que nos dois anos de estudo, em que foram analisados este componente, não foram encontradas diferenças significativas em seus valores quando submetidas à análise de teste de Tukey a $5 \%$ de probabilidade.

RC: 106378

Disponível em: https://www.nucleodoconhecimento.com.br/agronomia/adubacaopotassica 
Em relação a MMG, observa-se que tanto na safra 2019/20 como na safra 2020/2021 os valores médios da MMG ficaram abaixo dos apresentados pela empresa detentora da cultivar utilizada que seria de $145 \mathrm{gr}$.

Observa-se na figura 5 , que na safra $2019 / 20$ o maior valor (128,75 gr) foi encontrado no tratamento de testemunha ( $\mathrm{T} 1$ ), onde foi aplicado apenas adubo 02.23.23, porém não apresentou diferença estatística em relação aos valores dos demais tratamentos.

Na Safra $2020 / 21$ os maiores valores $(132,75 \mathrm{~g})$ foram encontrados no tratamento 4 , onde foi aplicado SFT + $\mathrm{KCl}$ (linha) + cálcio, porém não apresentou diferença estatística quando comparado aos demais tratamentos, como também em relação a testemunha.

Conforme Vogel (2016) em experimento no município de Cerro Largo com diferentes formas de aplicação potássica e fosfatada a lanço e na linha, também não obteve relação significativa em seus tratamentos no que diz respeito à massa de mil grãos.

Para Navarro Junior e Costa (2002) a massa média dos grãos é de característica que está fortemente relacionada à genética, sendo uma característica própria de cada cultivar, tornando-se modificável pelas condições do ambiente.

Em relação ao rendimento de grãos, pode-se observar na figura 6 os resultados obtidos nos dois anos de cultivo.

RC: 106378

Disponível em: https://www.nucleodoconhecimento.com.br/agronomia/adubacaopotassica 
Figura 6 - Rendimento de grãos nas safras 2019/20 e 2020/21

\begin{tabular}{|l|c|c|}
\multicolumn{1}{|c|}{ Tratamento } & $\begin{array}{c}\mathbf{2 0 1 9 / 2 0 2 0} \\
\left(\mathbf{k g ~ h a} \mathbf{~}^{-1}\right)\end{array}$ & $\begin{array}{c}\mathbf{2 0 2 0 / 2 0 2 0} \\
\text { (kg ha-1) }\end{array}$ \\
\hline T1 - Testemunha (N-P-K 02.23.23) & 2454,0 a & 4339,0 a \\
\hline T2 - N-P-K 02.23.23 + Cálcio & 2695,0 a & 4028,0 a \\
\hline T3 - SFT + KCI (linha) & 2348,0 a & 3967,0 a \\
\hline T4 - SFT + KCI (linha) + Cálcio & 2293,0 a & 4331,0 a \\
\hline T5 - SFT + KCI (lanço) & 2469,0 a & 4341,0 a \\
\hline T6- SFT + KCI (lanço) + Cálcio & 2532,0 a & 4276,0 a \\
\hline \multicolumn{1}{|c|}{ Média } & 2465,0 & 4214,0 \\
\hline C.V (\%) & 19,65 & 7,1 \\
\hline
\end{tabular}

Médias seguidas de mesma letra na coluna não diferem entre si no teste de tukey a 5\% de significância. Fonte: Klarmann; Silva; Jeziorski (2021)

Em relação ao rendimento de grãos da safra 2019/2020, observa-se que o maior rendimento ocorreu no tratamento em que foi utilizado NPK 02.23.23 + cálcio, com $2695 \mathrm{Kg} \mathrm{ha}^{-1}$, porém não apresentou diferença estatística em relação aos demais tratamentos.

Pode ser observado também que o rendimento médio dos tratamentos na safra 2019/2020 foi inferior à expectativa de rendimento, estabelecida em $3600 \mathrm{Kg} \mathrm{ha}^{-1}$, sendo afetada pelo baixo volume de chuvas durante o ciclo da cultura.

Malavolta (1980), afirma que os períodos de déficit hídrico na fase de desenvolvimento vegetativo reduzem o crescimento da planta, diminui a área foliar e o rendimento de grãos.

Ao citar o rendimento de grãos na safra 2020/2021 observa-se que o maior rendimento ocorreu no tratamento 5 , onde foi aplicado SFT $+\mathrm{KCl}$ (lanço), com uma produtividade de $4341 \mathrm{Kg}$ ha-1, enquanto o menor rendimento ocorreu no tratamento 3, em que foi aplicado SFT + KCl (linha), com rendimento de $3967 \mathrm{Kg}$ ha-1, porém estes valores não se diferiram estatisticamente diante dos demais tratamentos. 
Os resultados obtidos são semelhantes aos encontrados por Bernardi et al. (2009), onde afirmam não ter encontrado diferença significativa no rendimento de grãos em relação à forma de aplicação de potássio na cultura da soja em solo vermelho argiloso com nível de potássio classificado como alto.

Pettigrew (2008) afirma que podem-se obter respostas à adubação potássica sob diferentes manejos, desde que o solo apresente baixa disponibilidade do nutriente.

\section{CONCLUSÃO}

Através do presente estudo foi possível avaliar a influência dos efeitos do manejo de adubação potássica, com a adição ou não de cálcio, nos componentes de rendimento e rendimentos de grãos da cultura da soja em latossolo vermelho nos anos/safras 2019/20 e 2020/21.

Com o alcance dos objetivos propostos neste estudo, pode-se analisar as hipóteses formuladas conforme o exposto em sequência.

A primeira hipótese de que "a adubação potássica, quando realizada em superfície, a lanço, irá promover incrementos significativamente maiores no rendimento de grãos, em relação à aplicação no sulco de semeadura, em ambos os anos de cultivo" não se confirma, devido não haver diferença estatísticas entre as produtividades dos demais tratamentos em estudo, podendo ser explicado pelo fato de que os níveis de potássio encontrados originalmente no solo são classificados como muito alto pela Comissão de Química e Fertilidade do Solo RS/SC, 2016, sendo suficiente para suprir as exigências nutricionais da cultura.

Em relação à hipótese de que "os componentes de rendimento da soja no segundo cultivo são afetados significativamente pelos tratamentos nutricionais estudados" também não se confirmou para nenhum dos componentes de rendimentos analisados, visto que, através da realização do teste de Tukey a $5 \%$ de significância nos resultados obtidos na safra 2020/2021, foi possível verificar que não houve efeito significativo nos

Disponível em: https://www.nucleodoconhecimento.com.br/agronomia/adubacaopotassica 
componentes de rendimento dentre os tratamentos em estudo, como também não ocorreu diferença estatística destes mesmos componentes de rendimento no primeiro ano de cultivo.

Já, a hipótese de que "quando adicionada uma fonte de cálcio nos tratamentos realizados, ocorre aumento significativo na massa de mil grãos da soja em ambos os cultivos, independentemente do manejo da adubação potássica" também não se confirmou, pois não houve ocorrência de diferenças significativas para estes tratamentos.

A hipótese de que "o uso de uma fonte de cálcio no solo promove menor extração de potássio pelas plantas de soja aos 30, 60, 90 dias e pelos grãos, na condição do segundo cultivo, independentemente de sua forma de aplicação" não foi confirmada, uma vez que não houve diferenças significativas em relação a concentração de potássio na fitomassa da cultura aos 30,60 e 90 D.A.E, como também nos grãos colhidos.

Em relação a última hipótese, de que "o uso de uma fonte de cálcio por dois anos consecutivos, afeta de modo significativo o rendimento de grãos da soja no segundo cultivo, devido ao efeito residual desse elemento no solo" também não obteve confirmação, pois em nenhum dos tratamentos que receberam aplicação de cálcio foram encontradas diferenças significativas no rendimento de grãos na safra 2020/2021 em comparação aos tratamentos em que não receberam aplicação de cálcio.

Em resposta ao problema da pesquisa, pode-se afirmar que não houve diferenças significativas sobre componentes de rendimento e o rendimento de grãos pelos diferentes manejos de adubação potássica acrescida de adição anual de cálcio nas condições edafoclimáticas de Três de Maio, RS, safras 2019/2020 e 2020/2021, não apresentando diferenças significativas em relação a testemunha. 
Após a conclusão do estudo em tela, pode-se afirmar que o potássio, quando aplicado em superfície não acarreta incrementos de produtividade da cultura da soja em solos classificados como Latossolo Vermelho Distroférrico Típico com altos índices de fertilidade, contudo, o presente trabalho abre oportunidades de realização de outros estudos com objetivo de avaliar a influência das formas de aplicação de potássio na cultura da soja.

\section{REFERÊNCIAS}

BENITES, Vinicius de Melo; CARVALHO, Maria da Conceição; RESENDE, Álvaro Vilela; POLIDORO, José Carlos; BERNARDI, Alberto Carlos De Campos; OLIVEIRA, Fabio Alvares de. 0 potássio, o cálcio e o magnésio na agricultura brasileira. $I n$ : PROCHNOW, Luís Ignácio; CASARIN, Valter; STIPP, Silvia Regina. Boas práticas para uso eficiente de fertilizante. Piracicaba: IPNI. 2010. pp. 133-204.

BERNARDI, Alberto Carlos de Campos; OLIVEIRA JÚNIOR, Juarez Patrício de; LEANDRO, Wilson Mozena; MESQUITA, Tiago Gomes da Silva; FREITAS, Pedro Luiz de; CARVALHO, Maria da Conceição Santana. Doses e formas de aplicação da adubação potássica na rotação soja, milheto e algodão em sistema de plantio direto. Pesquisa Agropecuária Tropical. V. 39. n. 2. Goiânia: Universidade Federal de Goiânia. Abr./Jun. 2009.pp. 158-167.

CONAB. Acompanhamento da safra brasileira de grãos, safra 2019/2020. Brasília: Companhia Nacional de Abastecimento. 2020.

DALL'AGNOL, Amélio; ROESSING, Antonio Carlos; LAZZAROTTO, Joelsio José; HIRAKURI, Marcelo Hiroshi; OLIVEIRA, Arnold B. de. O complexo agroindustrial da soja brasileira. Circular Técnica 43. Londrina: EMBRAPA. 2007. ISSN 1516-7860.

EMBRAPA. Sistema brasileiro de classificação de solos. 3 ed. Brasília, DF. Embrapa informação tecnológica. 2013. ISBN 978-85-7035-198-2. 
FIORIN, Jackson Ernani; VOGEL, Pedro Toigo; BORTOLOTTO, Rafael Pivotto. Métodos de aplicação e fontes de fertilizantes para a cultura da soja. Revista Brasileira de Ciências Agrárias. V. 11. n. 2. Recife: Universidade Federal Rural de Pernambuco. Jun. 2016. pp. 92-97.

LOPES, Alfredo Scheid; GUILHERME, Luiz Roberto Guimarães. Fertilidade do solo e produtividade agrícola. In: NOVAIS, Roberto Ferreira de; ALVAREZ, Victor Hugo V; BARROS, Nairam Félix De; FONTES, Renildes Lúcio; CANTARUTTI, Reinaldo Bertola; NEVES, Júlio César Lima. Fertilidade do Solo. Viçosa: SBCS. 2007.

MALAVOLTA, Eurípedes. Manual de nutrição mineral de plantas. 1 ed. São Paulo: Editora Ceres. 2006. ISBN: 8531800471

. Nutrição mineral e adubação da soja. Piracicaba: Escola Superior de Agricultura Luiz de Queiroz. 1980.

MANTOVANI, Analu; RIBEIRO, Fernando José; VEIGA, Milton; ZILIO, Marcio; FELICIO, Tamara Pereira. Método de aplicação de potássio na soja em nitossolo vermelho. Unoesc \& Ciência. V. 8. n. 2. Joaçaba: Universidade do Oeste de Santa Catarina. Jul./dez. 2017. pp. 169 - 176.

MARCOS-FILHO, J. Fisiologia de sementes de plantas cultivadas. Piracicaba: FEALQ, 2005.

MELÉM JÚNIOR, Nagib Jorge; FABER, Jean; GALLO, Juliano; OLIVEIRA JUNIOR, Raimundo Cosme de; SILVA, Alessandra Damasceno da; OLIVEIRA, Daniel Rocha de. Avaliação da produtividade da soja em diferentes doses de potássio na região de Belterra/PA. Congresso Brasileiro de Ciência do Solo, 35. Natal. 2015.

MOORE, David. P; OVERSTREeT, Roy; JACOBSON, Louis. Aplicação de magnésio e sua interação em raízes de cevada. Plant physiology. V. 36. n. 3. Mai. 1961. pp. 290 - 295. 
NAVARRO JÚNIOR, Hugo. Motta; COSTA, José Antonio. Contribuição relativa dos componentes do rendimento para produção de grãos de soja. Revista Pesquisa Agropecuária Brasileira. V. 37. n. 3. Brasília. Jan. 2002. pp. 269 - 274.

PETER, Dieter Gustavo; VILAR, Cesar Crispim; USHIWATA, Silvio Yoshiharu; RODRIGUES, Orismário Lúcio. Modos de aplicação de fertilizantes formulado NPK na cultura da soja em sistema de plantio direto. Global Science Technology. V. 9. n.1. Rio Verde: Universidade do Estado de Mato Grosso. Jan./abr. 2016. pp. 48 $-55$.

PETTIGREW, William. Influências do potássio no rendimento e qualidade da produção de milho, trigo, soja e algodão. Physiologia Plantarum. V. 133. n. 4. Compenhagen. Jul. 2008. pp. 670 - 680.

PRADO, Renato De Mello. Nutrição de Plantas. São Paulo: UNESP. 2008. ISBN: 9788571396760.

RAIJ, Bernardo Van. Fertilidade do solo e manejo de nutrientes. Piracicaba: IPNI. 2011. ISBN: 9788598519074.

REETZ, Harold. Fertilizantes e seu uso eficiente. São Paulo: Associação Nacional para Difusão de Adubos. 2017. ISBN: 9791092366044.

TOMÉ, Paulo Capistrano Dias. Adubação a lanço versus na linha. 2019. [Online]. [Acessado em 07/11/2020] Disponivel em: $<w w w . p i o n e e r s e m e n t e s . c o m . b r / b l o g / / a d u b a c a o-a-l a n c o-v e r s u s-n a-l i n h a>$.

TROEH, Frederick; THOMPSON, Louise. Fertilidade do Solo. Tradução de DOURADO NETO, Durval; DOURADO, Manuella Nóbrega. São Paulo: Andrei. 2007. pp. 718

USDA. Produção, Fornecimento e Distribuição. United States Department of Agriculture. 2011.

RC: 106378

Disponível em: https://www.nucleodoconhecimento.com.br/agronomia/adubacaopotassica 
VOGEL, Luander Silmar Bourscheidt. Avaliação da produtividade de soja em função da forma de aplicação de cloreto de potássio e super fosfato triplo. Trabalho de conclusão de curso em agronomia. Universidade Federal da Fronteira Sul, Curso de Agronomia. 2016.

Enviado: Novembro, 2021.

Aprovado: Fevereiro, 2022. 